\title{
ESTÁDIOS PARA 2014
}

\section{Em 2014 o Brasil vai sediar a Copa do Mundo, e uma extensa agenda de investimentos está programada. Boa parte se refere à construção ou reforma de estádios nas 12 cidades-sede. Qual a viabilidade econômico-financeira desses projetos?}

Encerrada a Copa do Mundo na África do Sul, as atenções voltam-se agora para o Brasil, sede do próximo mundial. Se a expectativa para ver a bola rolar em gramados brasileiros é grande, maiores ainda são os investimentos públicos e privados a serem feitos nos próximos anos para viabilizar o evento. Neste artigo, fazemos um breve exercício com a finalidade de discutir o risco que os investimentos em estádios poderão trazer para o contribuinte e para a economia do país.

MEDIÇÃO DE IMPACTOS. Existem metodologias específicas para a mensuração dos efeitos econômicos de megaeventos esportivos como a Copa do Mundo, e elas costumam envolver a mensuração de impactos em dois momentos distintos. Antes do evento, faz-se uma avaliação ex ante, isto é, prospectiva, que leva em conta previsões dos gastos e investimentos, do fluxo de visitantes e seu dispêndio médio, dos efeitos indiretos que o evento poderá surtir sobre a economia, e assim por diante. Após o evento, é possível uma avaliação ex post, com base nos fatos.

De acordo com pesquisas, como por exemplo as dos economistas norte-americanos Victor Matheson e Robert Baade, os resultados em geral são bem menos espetaculares na análise ex post do que na ex ante. Em outras palavras, na sua maioria estes megaeventos são planejados com euforia e otimismo, mas seu retorno efetivo não costuma ser tão animador. O excesso de otimismo ex ante tem algumas razões típicas. Entre elas estão o "efeito substituição", quando parte dos dispêndios com o evento deixa de ser gasto em outros bens e serviços da economia local; o "efeito deslocamento", quando o congestionamento causado pelo evento pode dissuadir visitantes regulares ou turistas que não se interessam por ele; e os vazamentos de renda, quando uma parcela dos resultados do evento é apropriada fora da cidade ou do país que o sedia. 

Há, contudo, benefícios intangíveis cuja mensuração é mais complicada. O orgulho nacional, com o ganho de evidência do país-sede no contexto internacional, pode ser citado como um exemplo. Há também evidências de que até mesmo a produtividade dos trabalhadores pode aumentar após o evento, o que remete à lógica da política romana de "pão e circo".

Há ainda impactos financeiros mensuráveis, mas de consequências incertas, sobre as finanças públicas, quando os investimentos têm participação governamental. Para a realização dos Jogos Olímpicos de 2004, em Atenas, na Grécia, o custo do evento foi largamente subestimado. A urgência na realização das obras trouxe impactos fiscais significativos, e isso contribuiu para a deterioração da trajetória fiscal do país que se verificou nos anos seguintes.

INVESTIMENTO EM ESTÁDIOS. Os investimentos necessários à realização de um evento como a Copa do Mundo referem-se à construção e reforma de estádios, mas também a questões estruturais como mobilidade urbana, comunicações, infraestrutura urbana etc.
No caso de estádios - que optamos por discutir mais de perto neste artigo -, os projetos de investimento costumam ser bastante controversos. A Fifa estabelece requisitos a serem atendidos por estádios para sediarem jogos da Copa, mas preencher tais critérios exige grandes investimentos, especialmente no Brasil, onde a maioria dos estádios está defasada, boa parte deles tendo sido construída em meados do século passado, quando os requisitos eram bem menos rigorosos.

Além disso, projetos de estádios para a Copa possuem uma característica peculiar: não podem levar em consideração as receitas da própria Copa, que são atribuídas à Fifa. Dependem, assim, da geração de receitas com jogos regulares, e uma dificuldade nesse sentido é o gasto relativamente baixo dos torcedores com ingressos de jogos, mesmo no país do futebol.

A tabela abaixo apresenta estimativas do consumo atual com futebol nas 12 cidades que serão sedes do mundial, e as compara com os investimentos programados. Ela mostra o resultado de uma conta rápida: avaliamos quantos anos de receita de ingressos serão necessários para igualar os investimentos que já estão programados para a Copa, em cada cidade-sede. A estimativa de receita com ingressos em cada

\section{CÁLCULO DO TEMPO DE RECEITA NECESSÁRIO PARA IGUALAR O INVESTIMENTO EM ESTÁDIOS}

\begin{tabular}{|c|c|c|c|c|}
\hline & $\begin{array}{l}\text { Investimentos programados } \\
\text { em estádios (R\$ milhões) }\end{array}$ & $\begin{array}{l}\text { Dispêndio anual per capita } \\
\text { em ingressos (R\$) }\end{array}$ & $\begin{array}{l}\text { Receita anual em ingressos } \\
\text { de jogos ( } \mathrm{R} \$ \text { milhões) }\end{array}$ & $\begin{array}{l}\text { Anos de receita atual para } \\
\text { igualar o investimento } \\
\text { (Investimento/receita anual) }\end{array}$ \\
\hline Belo Horizonte & 426 & 6,3 & 31,2 & 14 anos \\
\hline Brasília & 745 & 4,8 & 11,7 & 63 anos \\
\hline Cuiabá & 454 & 2,4 & 1,3 & 357 anos \\
\hline Curitiba & 185 & 8,3 & 25,8 & 7 anos \\
\hline Fortaleza & 623 & 4,2 & 14,5 & 43 anos \\
\hline Manaus & 515 & 4,1 & 6,8 & 76 anos \\
\hline Natal & 350 & 2,3 & 1,8 & 193 anos \\
\hline Porto Alegre & 130 & 17,8 & 70,6 & 2 anos \\
\hline Recife & 530 & 1,5 & 5,3 & 100 anos \\
\hline Rio de Janeiro & 600 & 1,6 & 18,4 & 33 anos \\
\hline Salvador & 592 & 2,6 & 9,5 & 63 anos \\
\hline São Paulo & 240 & 5,1 & 98,2 & 2 anos \\
\hline Total das cidades & $5.389,30$ & 5,0 & 295,0 & 18 anos \\
\hline
\end{tabular}

FONTE: MINISTÉRIO DOS ESPORTES (INVESTIMENTOS PROGRAMADOS EM JULHO DE 2010) E CÁLCULOS DA PEZCO PESQUISA E CONSULTORIA LTDA. COM BASE EM EXTRAPOLAÇÃO DA PESQUISA DE ORÇAMENTO FAMILIAR DO IBGE (DISPÊNDIO) 
cidade foi construída a partir de dados da Pesquisa de Orçamento Familiar (POF), do IBGE.

Trata-se, evidentemente, apenas de um exercício, que desconsidera os custos de operação dos estádios, e também o fato de que nem toda receita de um estádio é dele próprio, tendo que ser compartilhada com os clubes. Sob essas hipóteses, na média as obras nos estádios da Copa levariam 18 anos para se pagar. Note-se que não foi usada nenhuma taxa de desconto nos cálculos, o que os torna ainda mais otimistas. Mesmo assim, na maior parte das cidades, os investimentos programados em estádios precisarão de várias décadas, ou mesmo de séculos, para se pagar.

\section{Um exercício simples mostra que, em várias cidades-sede, os projetos de investimento em estádios para a Copa oferecem risco de onerar os contribuintes}

Os casos de Cuiabá e Manaus - cidades que não possuem nenhum clube de futebol nas divisões principais - são particularmente emblemáticos. Acreditar que apenas a construção de estádios fará com que o futebol se desenvolva nessas localidades, a ponto de tornar-se um investimento atrativo, constitui uma hipótese absolutamente irrealista. Não por acaso, $100 \%$ dos investimentos programados para essas cidades são públicos, sem a participação de iniciativa privada.

Assim à primeira vista, portanto, os investimentos nos estádios da Copa de 2014 seriam financeiramente inviáveis. Para se tornarem viáveis, seus projetos devem levar em conta outros itens na sua modelagem econômicofinanceira. A maior parte dos estádios precisará alavancar um volume muito significativo de receitas assessórias, isto é, vindas de outras fontes que não a venda de ingressos para jogos. É o caso das receitas derivadas da realização de shows, venda de camarotes e espaços publicitários, venda de naming rights (direitos sobre o nome do estádio), arrendamento de espaços para lojas e centros comerciais, entre outras. Embora não devam ser desprezadas, essas receitas não costumam ser tão significativas. Algumas delas, como a dos shows, são necessariamente acompanhadas por fortes aumentos de custos.

Caso não seja possível assegurar um volume realmente significativo dessas receitas assessórias, a maioria dos estádios só será economicamente sustentável em um cenário de demanda por ingressos fortemente ampliada após o mundial. Para tanto, é necessário supor que, com estádios maiores e mais modernos, haverá uma verdadeira explosão da frequência, e o futebol se tornará um programa de lazer regular e preferencial da família brasileira, mesmo naquelas cidades em que o futebol não é atração principal.

DESAFIOS. Embora o apresentado aqui seja apenas um exercício simplificado, ele permite ver que a Copa de 2014 oferece o risco real de onerar os contribuintes com investimentos públicos em função de estimativas equivocadas, ou demasiadamente otimistas.

Para minorar o risco, é preciso cuidar não somente de boas estimativas da relação custo-benefício, mas também de instrumentos de boa gestão dos investimentos públicos previstos, que são volumosos. Assegurar as receitas assessórias - das quais dependerá a sustentabilidade econômica da maior parte dos projetos - deve ser um foco prioritário de atenção. A participação do setor público nos investimentos requer avaliações cuidadosas, e não se deve perder de vista que as projeções otimistas normalmente apresentadas antes de um evento deste tipo costumam, com frequência, resultar em relatórios retrospectivos bem mais modestos.

Por fim, um aspecto importante a ser lembrado é o fato de o Brasil ter preferido 12 cidades-sede, ao passo que a Fifa só exige oito. Os investimentos em estádios poderiam ter sido fortemente reduzidos, tornando o cenário menos arriscado. Restanos torcer para que, dessa vez, o Brasil se torne hexacampeão. Assim, no pior dos casos, pagaremos a conta festejando.

FREDERICO ARAUJO TUROLLA,

professor da FGV-EESP, frederico.turolla@fgv.br

MARCIO FERNANDES GABRIELLI,

professor da FGV-EAESP, marcio.gabrielli@fgv.br 